\title{
Influence of socioeconomic conditions on air pollution adverse health effects in elderly people: an analysis of six regions in São Paulo, Brazil
}

\author{
M C H Martins, F L Fatigati, T C Véspoli, L C Martins, L A A Pereira, M A Martins, P H N Saldiva, \\ A L F Braga
}

See end of article for authors' affiliations

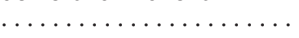

Correspondence to: Professor A L F Braga,

Programa de Pediatria Ambiental, Faculdade de Medicina de Santo

Amaro-UNISA/, Hospital Geral do Grajaú, Rua Francisco Octávio Pacca, 180, $4^{\circ}$ Andar, CEP 04822-320, Grajaú, São Paulo, SP, Brazil; abraga@unisa.br

Accepted for publication 27 May 2003
Study objective: To evaluate if the effects of particulate matter $\left(\mathrm{PM}_{10}\right)$ on respiratory mortality of elderly people are affected by socioeconomic status.

Design: Time series studies. The daily number of elderly respiratory deaths were modelled in generalised linear Poisson regression models controlling for long term trend, weather, and day of the week, from January 1997 to December 1999, in six different regions of São Paulo City, Brazil. The regions were defined according to the proximity of air pollution monitoring stations. Three socioeconomic indicators were used: college education, monthly income, and housing.

Main results: For a $10 \mu \mathrm{g} / \mathrm{m}^{3}$ increase in $\mathrm{PM}_{10}$, the percentage increase in respiratory mortality varied from $1.4 \%(95 \% \mathrm{Cl} 5.9$ to 8.7$)$ to $14.2 \%(95 \% \mathrm{Cl} 0.4$ to 28.0$)$. The overall percentage increase in the six regions was $5.4 \%(95 \% \mathrm{Cl} 2.3$ to 8.6$)$. The effect of $\mathrm{PM}_{10}$ was negatively correlated with both percentage of people with college education and high family income, and it was positively associated with the percentage of people living in slums.

Conclusions: These results suggest that socioeconomic deprivation represents an effect modifier of the association between air pollution and respiratory deaths.
$\mathrm{T}$ he health effect of air pollution is a subject of public concern, as numerous studies have shown a significant association between daily fluctuations of air pollution and health indicators such as mortality and morbidity. ${ }^{1-3}$ The most robust associations in this area were obtained with atmospheric particles, mainly those below $10 \mu \mathrm{m}\left(\mathrm{PM}_{10}\right)$, which present the highest pulmonary deposition rate. ${ }^{45}$ Risk groups were clearly identified among the exposed population: children, elderly people, and those with pre-existing cardiopulmonary diseases..$^{6-8}$ In addition to age and disease status socioeconomic conditions may modify the effect of air pollution. Using a cross sectional analysis in São Paulo, Brazil, Sobral ${ }^{9}$ suggested that morbidity associated with air pollution is higher in areas with low economic income. More recently, Zanobetti and Schwartz ${ }^{10}$ used a time series study and found that the degree of education on the individual level was a modest modifier of the effect of $\mathrm{PM}_{10}$ on mortality in four US cities. The proper evaluation of the interaction between air pollution and socioeconomic deprivation contributes to the discussion on "environmental justice", a movement that has striven for healthier environments for the most polluted communities in the US and in other countries. ${ }^{11} 12$

In the city of São Paulo the presence of detectable health effects in repeated animal ${ }^{13}{ }^{14}$ and epidemiological studies using total elderly deaths, ${ }^{8}$ children respiratory deaths, ${ }^{15}$ fetal deaths, ${ }^{16}$ paediatric emergence room visits, ${ }^{17}$ and children respiratory hospital admissions ${ }^{18}{ }^{19}$ indicate that air deterioration represents a significant public health problem.

Our purpose in this study was to evaluate if socioeconomic status modifies the effects of $\mathrm{PM}_{10}$ on mortality of elderly people. For such purpose, we performed time series studies in six different regions of São Paulo City, grouped by the proximity of air pollution monitoring stations, but that also present differences in their socioeconomic profiles.

\section{METHODS}

\section{Data collection}

The Municipal Mortality Information Improvement Program (PRO-AIM) provided daily records of mortality attributable to respiratory diseases (ICD 10th Revision: J00-J9920 ${ }^{20}$ for people 60 years of age and older, from January 1997 to December 1999. Children and elderly people typically move about the city less than other age groups. Firstly, at 60 most of them are retired or unemployed. Differently from developed countries, where retirement means time to spend travelling or having an easier period of time, in Brazil, for most of the people, retirement means less money to do whatever you want. Secondly, public transportation is of low quality and it is not adapted to receive elderly people with a minimum of comfort and security. The elderly population often avoid frequent movement around the city. Also, the increasingly urban violence is an important factor that keeps elderly people at home. Aging in an environment like that leads to social isolation. Therefore, they are predominantly exposed to the air pollution of their own neighbourhood. This database included information on cause and day of the death, person's age, and address.

São Paulo State Sanitary Agency (CETESB) provided daily means (24 hour averages) of $\mathrm{PM}_{10}$, measured by nine air monitoring stations, and daily records of temperature and humidity measured in two stations located in downtown and east region. The Institute of Astronomy and Geophysics of the University of São Paulo provided data on temperature and humidity from the south region of the city.

We used the most updated socioeconomic data available in São Paulo provided by The Subway Company of São Paulo,

Abbreviations: OD, origin-desitnation zone; PRO-AIM, Municipal Mortality Information Improvement Program 


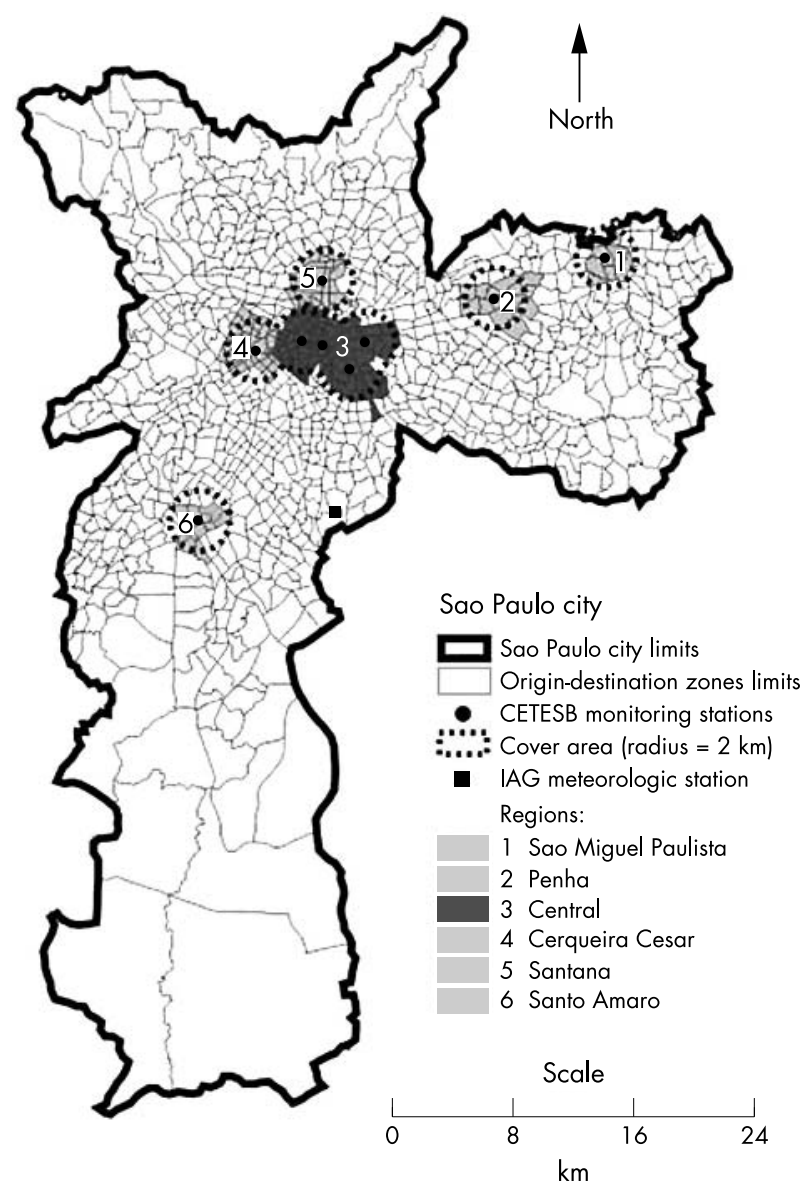

Figure 1 São Paulo City map with origin-destiny (OD) zones and the six regions of the study.

responsible for the management of the city's subway. In October 1997, it carried out a survey by sampling of domiciles and 26845 families were interviewed to study socioeconomic status and routes of its passengers within the metropolitan region of São Paulo. Data were grouped by geographical areas-270 inside the city-called origin-destination zones (OD zones), which are subdivisions of 96 city administrative districts. Therefore, these OD zones are smaller and more homogeneous than the 96 administrative districts of São Paulo usually used in previous studies. ${ }^{21} 22$ They are too large to be socially homogeneous. These data are compatible with the results of the demographic census. Socioeconomic information included education (percentage of people with college education), age, housing conditions (percentage of people living in slums), and family income (percentage of families with income bigger than U\$ 3500-at that time one dollar was equal to one real, the Brazilian currency). In our society, income does not determine family size as is seen in developed countries. In São Paulo City, the poorer regions present the higher number of persons by family. Hence, the use of family income as measure of poverty was appropriate. Figure 1 shows a map of São Paulo with OD zones.

\section{Definition of the areas in the study}

We defined circles with $2 \mathrm{~km}$ radii around nine air quality monitoring stations (cover areas). As some stations were too close and their cover areas overlapped (Central) we grouped them in one region. In the Central area, the mean values of $\mathrm{PM}_{10}$ of the corresponding four monitoring stations were averaged and adopted as representative of the whole area. Each region was composed of OD zones. We included an OD zone in a cover area if at least two thirds of its territory were within the station cover area. The defined regions (and the number of OD zones included) were São Miguel Paulista (3), Penha (4), Central (23), Cerqueira Cesar (7), Santana (6), and Santo Amaro (3) (fig 1). This work was performed using Geographical Information System software (Maptitude 4.0, Caliper Co).

To calculate the number of deaths by OD zones, and therefore by regions, we plotted each death on a São Paulo City map according to deceased's residence address using a Geographical Information System software (MapInfo 5.5, MapInfo Co). After that the software counted and grouped the number of death by region.

The number of people with high education in a given region was the sum of the people with high education in each OD zone included in that region. The same approach was adopted for the others indicators.

\section{Statistical analysis}

We modelled counts of daily deaths in Poisson regression in each region. The generalised linear model ${ }^{23}$ with natural cubic splines $^{24}$ was adopted to control for season and weather. Splines were used to account for the non-linear dependence of the deaths on those covariates.

For each covariate we needed to choose the number of degrees of freedom to use. The purpose of the function of time is to remove the basic seasonal pattern (and long term trend) from the data. If this is done well, we would expect no remaining serial correlation in the data, as each death is an independent event. We used a separate smoothing parameter for time in each region assuming those seasonal patterns can vary between the six regions of the study. When the autocorrelation plots showed there were remaining serial correlation in the residuals we incorporated autoregressive terms ${ }^{25}$ in the models.

In each region, we chose the number of degrees of freedom for minimum temperature (two day moving average) and relative humidity (two day moving average) by minimising Akaike's information criteria (AIC). ${ }^{26}$ As we did not have

Table 1 Population in 1998 and socioeconomic indicators in the six regions of the study (1997-1999)

\begin{tabular}{|c|c|c|c|c|c|c|}
\hline \multirow[b]{2}{*}{ Regions } & \multicolumn{3}{|c|}{ Population 1998} & \multirow[b]{2}{*}{ Slums* $(\%)$} & \multirow[b]{2}{*}{ Education† (\%) } & \multirow[b]{2}{*}{ Income $(\%)$} \\
\hline & Total & Elderly§ & Elderly/Total (\%) & & & \\
\hline Cerqueira César & 184710 & 34947 & 18.92 & 0.00 & 33.92 & 46.20 \\
\hline Santo Amaro & 28633 & 4564 & 15.94 & 1.54 & 20.21 & 26.66 \\
\hline Central & 412199 & 71929 & 17.45 & 0.50 & 17.97 & 19.56 \\
\hline Penha & 183777 & 20638 & 11.23 & 4.15 & 8.39 & 10.13 \\
\hline Santana & 77739 & 12127 & 15.60 & 1.36 & 13.55 & 14.66 \\
\hline São Miguel Paulista & 104960 & 8974 & 8.55 & 10.99 & 6.36 & 5.58 \\
\hline Total & 992018 & 153179 & 15.44 & & & \\
\hline
\end{tabular}

*Percentage of people living in slums; tpercentage of people with college education; fpercentage of families with monthly income bigger than US\$ 3500 in 1997 ; $\$ 60$ years of age and older. 
Table 2 Descriptive analysis of total and respiratory deaths in the six regions of the study (1997-1999)

\begin{tabular}{llll}
\hline \multirow{2}{*}{ Regions } & \multicolumn{3}{l}{ Respiratory deaths (1997-1999) } \\
\cline { 2 - 4 } & Total & Mean* & SD† \\
\hline Cerqueira César & 371 & 0.34 & 0.59 \\
Santo Amaro & 69 & 0.06 & 0.25 \\
Central & 927 & 0.85 & 0.96 \\
Penha & 359 & 0.33 & 0.58 \\
Santana & 147 & 0.13 & 0.37 \\
São Miguel Paulista & 118 & 0.11 & 0.33 \\
Total & 1991 & 1.82 & 1.43 \\
\hline
\end{tabular}

*Daily mean of respiratory deaths; †standard deviation of mean.

temperature and humidity measured in every one of the six regions, we adopted temperature and humidity measured in the central region for itself and two other regions-that is, Cerqueira Cesar and Santana. For São Miguel and Penha, we adopted São Miguel station's weather data and for Santo Amaro we adopted IAG station's data. To capture short term potential confounding, we controlled for days of the week. To reduce sensitivity to outliers in the dependent variable we used robust regression (M-estimation).

To explore the lagged effect of $\mathrm{PM}_{10}$ on respiratory mortality we used air pollution levels at the concurrent day as well as moving averages ranging from two to seven days before.

Results were expressed in terms of percentage increase in respiratory mortality attributable to a $10 \mu \mathrm{g} / \mathrm{m}^{3}$ increase in $\mathrm{PM}_{10}$ concentration. The $95 \%$ confidence intervals were estimated assuming normality of the residuals. We used inverse variance weighted average ${ }^{10}$ to combine results across regions.

We adopted Spearman rank order correlation to explore the correlation between $\mathrm{PM}_{10}$ effect on respiratory mortality and socioeconomic indicators.

SPSS (version 10.0) was used to create the dataset and SPlus (version 4.5) was used to carry out the statistical analyses.

\section{RESULTS}

Table 1 shows the population and socioeconomic indicators in each one of the six regions during the period of study. The central region was the most populated, while Cerqueira Cesar presented the highest proportion of elderly people. The further the region was from the central area of the city (fig 1), the younger the population, and the worst the socioeconomic indicators.

The daily means of respiratory deaths in the six regions of the study from 1997 to 1999 were always smaller than one (table 2).

Table 3 presents the descriptive statistics of $\mathrm{PM}_{10}$ and weather variables. The number of days with $\mathrm{PM}_{10}$ measurements was different in each region. In the central region,
$\mathrm{PM}_{10}$ was measured every day during the period of study, while Santana was the region with fewer records. Central and Santana were the most polluted areas and Penha was the cleanest.

$\mathrm{PM}_{10}$ was negatively and significantly correlated with weather variables in all regions. For humidity, the correlation was greater than that observed for temperature.

Figure 2 presents the estimated percentage increase and $95 \%$ confidence intervals in daily respiratory deaths attributable to a $10 \mu \mathrm{g} / \mathrm{m}^{3}$ increase in the three day moving average of $\mathrm{PM}_{10}$ in each region. In São Miguel Paulista the estimated particulate effect was 10 times higher than the estimated effect on Cerqueira Cesar, although the ratio of their mean levels of $\mathrm{PM}_{10}$ was 1.6.

The effect of $\mathrm{PM}_{10}$ on respiratory mortality was strongly and negatively correlated (Spearman's rank order correlation) with two socioeconomic indicators: percentage of people with college education $(-0.94, \mathrm{p}<0.01)$ and family income $(-0.94, \mathrm{p}<0.01)$. On the other hand, the higher the percentage of people living in slums, the higher the $\mathrm{PM}_{10}$ effect on mortality (0.71), although this trend was not significant. The mean concentration of $\mathrm{PM}_{10}$ in each region presented positive correlation with the effect but it was smaller than the correlation presented by socioeconomic indicators and non-significant (0.6). A spatial view of these correlations can bee seen in figure 3 .

\section{DISCUSSION}

This study showed that the effects of $\mathrm{PM}_{10}$ on health differ within the urban area of São Paulo. Areas with lower socioeconomic profile presented the higher coefficients of the association between $\mathrm{PM}_{10}$ and mortality. Moreover, our study showed that the magnitude of the estimated effect of $\mathrm{PM}_{10}$ exhibited dose-response behaviour with estimators of poverty. In other words, the lower the socioeconomic status of the region the higher the air pollution effect on respiratory mortality, as shown in figure 3.

The methodology applied in this study is in agreement with the standard adopted for time series analysis. Also, we adopted in the models a set of confounders, including weather and season that have been the most commonly used for the association between $\mathrm{PM}_{10}$ and respiratory diseases. However, the possibility of incomplete adjustment for confounders must be considered.

Originally, we performed analyses using generalised additive models and non-parametric smooth functions, instead of natural cubic splines, to control for long term trend and weather. We adopted the same set of controls and we performed models specification according to standard methodological approach adopted in our previous studies using GAM and loess. ${ }^{1927} 28$ We did not observe relevant differences either in effects or in standard errors we obtained through the two approaches. For instance, the overall percentage increase estimates in both methods were around $5 \%$. This double check reinforces our results and avoids

Table 3 Descriptive analysis of $\mathrm{PM}_{10}$ and weather variables by regions of the study (1997-1999)

\begin{tabular}{|c|c|c|c|c|c|c|c|c|c|}
\hline \multirow[b]{2}{*}{ Region } & \multicolumn{3}{|c|}{$P M_{10}{ }^{*}\left(\mu \mathrm{g} / \mathrm{m}^{3}\right)$} & \multicolumn{3}{|c|}{ Temperature $\left.{ }^{\circ}{ }^{\circ} \mathrm{C}\right)$} & \multicolumn{3}{|c|}{ Humiditył (\%) } \\
\hline & Mean§ & SDף & $\mathrm{N}^{* \star}$ & Mean & SD & $\mathrm{N}$ & Mean & SD & $\mathrm{N}$ \\
\hline Cerqueira Cesar & 42.5 & 22.9 & 1010 & 17.1 & 3.2 & 1048 & 79.9 & 12.1 & 1048 \\
\hline Santo Amaro & 49.6 & 32.1 & 748 & 15.3 & 3.3 & 1095 & 81.1 & 8.2 & 1095 \\
\hline Central & 52.1 & 23.5 & 1095 & 17.1 & 3.2 & 1048 & 79.9 & 12.1 & 1048 \\
\hline Penha & 40.4 & 23.8 & 1075 & 16.4 & 3.2 & 1071 & 84.1 & 10.1 & 1071 \\
\hline Santana & 72.6 & 24.5 & 587 & 17.1 & 3.2 & 1048 & 79.9 & 12.1 & 1048 \\
\hline São Miquel Paulista & 68.6 & 31.0 & 922 & 16.4 & 3.2 & 1071 & 84.1 & 10.1 & 1071 \\
\hline
\end{tabular}

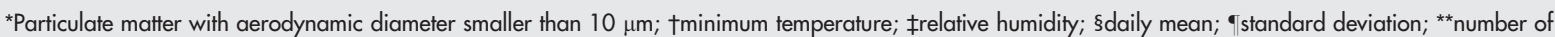
days with measurements. 


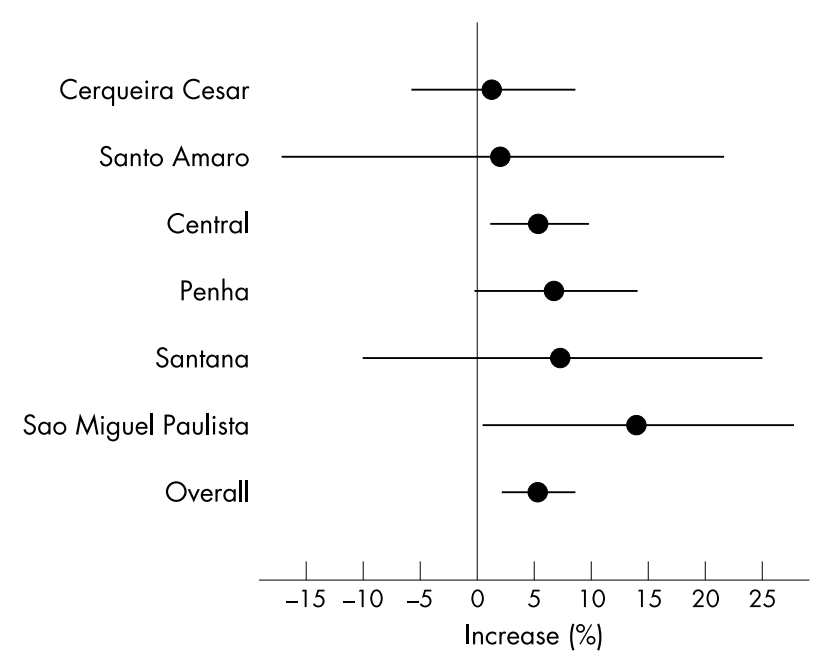

Figure 2 Percentage increase (and $95 \% \mathrm{Cl}$ ) in daily respiratory deaths attributable to a $10 \mu \mathrm{g} / \mathrm{m}^{3}$ increase in three day moving average of $\mathrm{PM}_{10}$ concentration in each region.

speculation on how the methodology adopted by the authors could influence the estimated effects.

We used $\mathrm{PM}_{10}$ in this study because this is the only pollutant measured in all 13 monitoring stations of the city. Also, $\mathrm{PM}_{10}$ is strongly associated with respiratory deaths in elderly people. ${ }^{8}$ The lag structure between air pollution exposure and respiratory and cardiovascular deaths has been assessed by Braga and colleagues ${ }^{29}$ and they have demonstrated that the most important contribution to respiratory deaths can be attributed to concentrations of one and two days before the death. Therefore, adopting the three day moving average looks plausible.

Although the sources of $\mathrm{PM}_{10}$ in São Paulo are dominated by automotive emissions and, therefore, it is spread all over the city, $\mathrm{PM}_{10}$ concentrations are not equal in the studied regions. However, as presented in the Spearman correlation analysis, mean $\mathrm{PM}_{10}$ concentration in each region was not the best factor to explain effect differences among the regions.

Effect differences by regions could also be induced by differences in air pollution composition. However, as mentioned elsewhere, monitoring stations do not monitor all pollutants and potential differences on pollutants mixture composition cannot be assessed. Moreover, all monitoring sites used in this study are traffic sites, located in avenues or streets with high traffic of cars, buses, and trucks.

Our study took advantage of the data computed by the Subway Company of São Paulo, which provided data within a much smaller area than the conventional administrative districts of the city. Thus, it was possible to characterise the socioeconomic conditions of a given area with a better resolution. This possibility, in parallel with the delimitation of the exposure level in a comparatively small distance from the measurement point (about $2 \mathrm{~km}$ ), proved to be of value when evaluating the regional differences in the effects of air pollution on health. Although Sobral ${ }^{9}$ had compared air pollution effects between areas within and without São Paulo City, using different study design and end points, she adopted the same criteria to define air pollution exposure (an area with $2 \mathrm{~km}$ of radius surrounding an air pollution monitoring station). She found a higher prevalence of respiratory diseases among children of low income families that lived in highly polluted areas. Perhaps, the study design used by us was responsible for the differences observed between our study and that of Gouveia and Fletcher. ${ }^{21}$ They found no significant influence of socioeconomic conditions on the health effects of air pollution in São Paulo City. Gouveia and Fletcher considered all cause mortality in the elderly population and used the administrative district as the geographical area of demographic information. In some administrative districts of São Paulo there are people with very heterogeneous socioeconomic conditions. Besides, for each pollutant, they used only one indicator of air pollution exposure-that is, the average of all station measures, for all regions of the city.

Zanobetti and Schwartz ${ }^{10}$ in a time series study looking at the effect modification induced by social factors on the association between daily deaths and $\mathrm{PM}_{10}$, found a small effect modification attributable to years of education that was considered by chance. They used two categories of years of education-that is, more or less than 12 years of school. As pointed by the authors, education is one of the most important social factors in health because it is related to income, class, degree of control in job, etc. However, the socioeconomic differences between people with more or less than 12 years of education cannot be enough to induce relevant differences in the susceptibility to $\mathrm{PM}_{10}$.

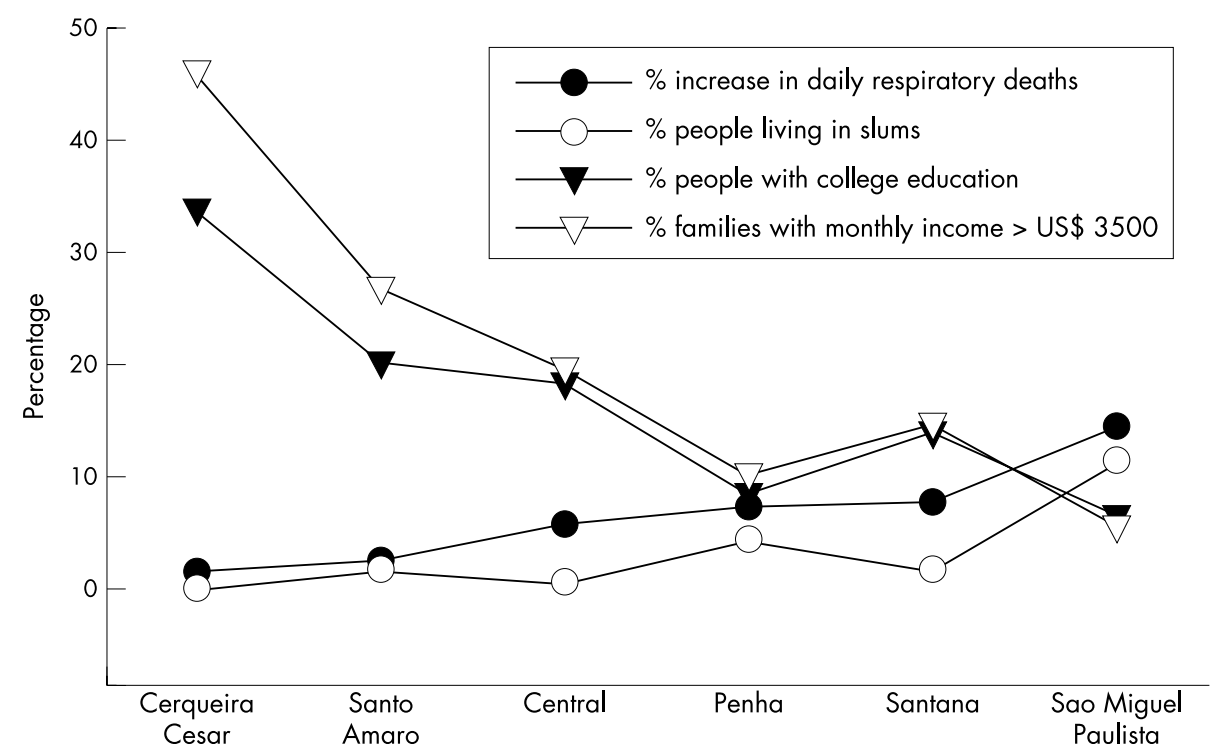

Figure 3 Percentage increase in daily respiratory deaths attributable to a $10 \mu \mathrm{g} / \mathrm{m}^{3}$ increase in three day moving average of $\mathrm{PM}_{10}$ and socioeconomic indicators in each region of the study. 


\section{Key points}

- This paper shows that even in a well known susceptible group of people air pollution health effects are not homogenous and differences in the magnitude may be inversely associated with socioeconomic status.

- In developing countries like Brazil, where the percentage of the population living in low socioeconomic conditions is considerable, the impact of air pollution exposure on public health has the potential to be larger than that observed in developed countries.

- $\mathrm{PM}_{10}$ were associated with respiratory mortality in all regions.

- Socioeconomic status modified the effect of $\mathrm{PM}_{10}$ on elderly respiratory mortality.

Also, effect modification by socioeconomic status has been observed in cohort study. Hoek and colleagues ${ }^{30}$ found that the higher the education level the lower is the impact of air pollution on mortality in Netherlands.

Despite the possible implications of our results in terms of environmental policy, the limitations of our dataset does not permit the identification of the cause(s) of the effect modification of socioeconomic conditions on $\mathrm{PM}_{10}$ effect. Poverty is associated with multiple variables that can influence health conditions. Bad sanitation, limited access to health services, impaired perception of health conditions, and poor housing conditions usually occur together and each one could explain our results. Moreover, malnutrition may modulate susceptibilities. Abbey and colleagues ${ }^{31}$ reported an increase of the $\mathrm{PM}_{10}$ effect on non-malignant respiratory deaths induced by low antioxidant vitamin intake among California Seventh Day Adventists.

If our results are in fact true, we may propose that health policies should be implemented differentially, on the basis of regional differences of susceptibility to airborne pollutants, to preserve public health. We can also suggest that safety of air pollution levels may be established in different levels, depending of social variables. Of course, our results are preliminary and cannot clarify such topics definitively. However, every regulatory policy should start from some point and we hope that our results could help such decision making.

Despite the inherent limitations of ecological studies we have been very discerning on the methodology adopted and on the conclusions we took from that. The larger the number of areas to compare the stronger the power of the analysis. However, even for a city like São Paulo, with one of the biggest monitoring networks in the world and huge social disparities it was impossible to work with a bigger number of regions. In future studies two levels of analysis can be adopted to refine the socioeconomic classification at the ecological level and specifying who is dying because of air pollution adverse health effects. The first point can be investigated using geographical information system analysis and adopting even smaller and more homogeneous areas within the city. This tool has remarkable relevance for ecological studies. The second point may be investigated using cohort and/or panel studies of people with different socioeconomic status.

In conclusion, we found that socioeconomic status is a significant modifier of air pollution effects on elderly mortality. The results are indicative that low economic income and low education augments the estimated coefficients relating $\mathrm{PM}_{10}$ to respiratory mortality in this age group.
Policy implications

- Reducing substantially air pollution health effects in São Paulo and in similar scenarios entails high investment in technology and strong and focused efforts of public authorities on social improvements to reduce exposure and susceptibilities, respectively.

These results reinforce the idea that poverty represents an important risk factor that should be taken into account when determining the health consequences of environmental contamination.

\section{ACKNOWLEDGEMENTS}

We thank the São Paulo City's Mortality Information Program (PROAIM), the São Paulo State Sanitary Agency (CETESB), the Subway Company of São Paulo, and São Paulo City Health, Environment and Planning Departments.

\section{Authors' affiliations}

M C H Martins, São Paulo City Health Departments, Brazil

F L Fatigati, São Paulo City Environment Departments, Brazil

T C Véspoli, São Paulo City Planning Departments, Brazil

L C Martins, L A A Pereira, P H N Saldiva, Laboratory of Experimental Air Pollution, Department of Pathology, University of São Paulo Medical School, Brazil

M A Martins, Laboratory of Experimental Air Pollution Department of Medicine, University of São Paulo Medical School

A L F Braga, Environmental Paediatrics Program, University of Santo Amaro Medical School, São Paulo, Brazil

Funding: LIM05 and LIM20-FMUSP, UNISA, and São Paulo City Health Department supported this work.

Conflicts of interest: none declared.

\section{REFERENCES}

1 Schwartz J. Air pollution and hospital admissions for heart disease in eight US counties. Epidemiology 1999;1:17-22.

2 Bobak M, Leon DA. Air pollution and infant mortality in Czech Republic, 1986-88. Lancet 1992;340:1010-14.

3 Dockery DW, Pope AC 3rd, Xu X, et al. $\mathrm{n}$ association between air pollution and mortality in six U.S. cities. N Engl J Med 1993:324:1753-9.

4 Wordley J, Walters S, Ayres JG. Short-term variations in hospital admissions and mortality and particulate air pollution. Occup Environ Med 1997;54:108-16.

5 Ostro B, Chestnut L, Vichit-Vadakan N, et al. The impact of particulate matter on daily mortality in Bangkok, Thailand. J Air Waste Manag Assoc 1999;49:100-7.

6 Ito K, Thurston GD. Daily PM10/mortality associations: a investigation of atrisk subpopulations. J Expo Anal Environ Epidemiol 1996;6:79-95.

7 Conceição GMS, Miraglia SGEK, Kishi HS, et al. Air pollution and child mortality: a time-series study in São Paulo, Brazil. Environ Health Perspect 2001;109:347-50.

8 Saldiva PHN, Pope AC 3rd, Schwartz J, et al. ir pollution and mortality in elderly people: a time-series study in São Paulo, Brazil. Arch Environ Health 1995;50:159-63.

9 Sobral HR. Air pollution and respiratory diseases in children in São Paulo, Brazil. Soc Sci Med 1989;29:959-64.

10 Zanobetti A, Schwartz J. Race, gender, and social status as modifiers of the effects of PM10 on mortality. J Occup Environ Med 2000;42:469-74.

11 The American Lung Association. Urban air pollution and health inequalities: a workshop report. Environ Health Perspect 2001;103(suppl 3):357-74.

12 ESRC Global Environmental Change Programme. Environmental justice: rights and means to a healthy environment for all. Special briefing no 7. Brighton: University of Sussex, 2001.

13 Pereira PM, Saldiva PHN, Sakae RS, et al. Urban levels of air pollution increase lung responsiveness in rats. Environ Res 1995;69:96-101.

14 Lemos M, Lichtenfels AJFC, Amaro E ir, et al. Quantitative pathology of nasal passages in rats exposed to urban levels of air pollution. Environ Res 1992;66:87-95.

15 Saldiva PHN, Lichtenfels AJFC, Paiva PSO, et al. Association between air pollution and mortality due to respiratory diseases in children in São Paulo, Brazil: a preliminary report. Environ Res 1994;65:218-25.

16 Pereira LAA, Loomis D, Conceição GMS, et al. Association between air pollution and intrauterine mortality in São Paulo, Brazil. Environ Health Perspect 1998;106:325-9. 
17 Lin CA, Martins MA, Farhat SC, et al. Air Pollution and respiratory illness of children in São Paulo, Brazil. Paedriatr Perinat Epidemiol 1999;13:475-88.

18 Braga ALF, Conceição GMS, Pereira LAA, et al. Air pollution and paediatric respiratory hospital admissions in São Paulo, Brazil. J Environ Med 1999; 1:95-102.

19 Braga ALF, Saldiva PHN, Pereira LAA, et al. Heath effects of air pollution exposure on children and adolescents in São Paulo, Brazil. Pediatr Pulmonol 2001;31:106-13

20 WHO. International classification of diseases, 10th revision. Vol 1. Geneva: World Health Organisation, 1993.

21 Gouveia N, Fletcher T. Time series analysis of air pollution and mortality: effects by cause, age and socioeconomic status. J Epidemiol Community Health 2000;54:750-5.

22 Drumond M Jr Lira MMTA Nitrini TMV et al Cardiovascular disease: some aspects of the filling out of the death certificate and the mortality profile in the city of São Paulo, Brazil. [In Portuguese]. Rev Soc Cardiol Estado de São Paulo 2001;1:191-202

23 McCullagh P, Nelder JA. Generalized linear models, 2nd edn. London: Chapman and Hall, 1989.

24 Green PJ, Silverman BW. Nonparametric regression and generalized linear models. A roughness penalty approach. London: Chapman and Hall, 1994.
25 Brumback BA, Ryan LM, Schwartz J, et al. Transitional regression models with application to environmental time series. J Am Stat Assoc 2000;95:16-28.

26 Akaike H. Information theory and an extension of the maximum likelihood principal. In: Petrov BN, Csaki F, eds. Second international symposium on information theory. Budapest: Akademiai Kiado, 1973:267-81.

27 Braga ALF, Zanobetti A, Schwartz J. The effect of weather on respiratory and cardiovascular deaths in 12 US cities. Environ Health Perspect 2002;110:859-63.

28 Martins LC, Latorre MRDO, Saldiva PHN, et al. Air pollution and emergency room visits due to chronic lower respiratory diseases in the elderly: an ecological time-series study in São Paulo, Brazil. J Occup Environ Med 2002;44:622-7.

29 Braga ALF, Zanobetti A, Schwartz J. The lag structure between particulate air pollution and respiratory and cardiovascular deaths in ten US cities. J Occup Environ Med 2001:43:927-33.

30 Hoek G, Brunekreef B, Goldbohm S, et al. Association between mortality and indicators of traffic-related air pollution in the Netherlands: a cohort study. Lancet 2002;360:1203-9.

31 Abbey DE, Nishino N, McDonnell WF, et al. Long-term inhalable particles and other air pollutants related to mortality in non-smokers. Am J Respir Crit Care Med 1999;159:373-82.

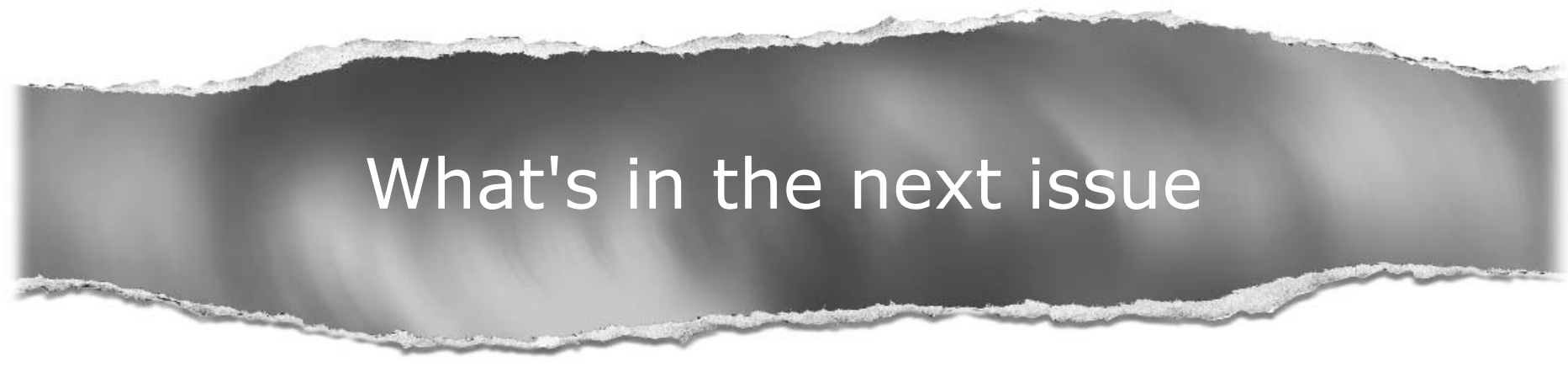

\section{Future content}

See which articles have just been accepted for publication and preview the table of contents for the next issue a month before it is published

\section{www.jech.com}

